\title{
Modified inspiratory flow pattern - a tool for lung protective ventilation
}

\author{
B Jonson ${ }^{1 *}$, LW Sturesson², G Malmkvist ${ }^{2}, S$ Allvin'², M Collryd ${ }^{2}$, M Bodelsson $^{2}$ \\ From ESICM LIVES 2015 \\ Berlin, Germany. 3-7 October 2015
}

\section{Introduction}

Lung protective ventilation, LPV, is recommended for ever wider patient populations, even those without primary lung disease. Low tidal volume ventilation is a first-hand remedy for LPV that is facilitated by dead space reduction. Inspiratory flow pattern affects gas exchange. In ARDS patients, it was recently shown that a long period during which inspired tidal gas is in contact with resident alveolar gas, mean distribution time, MDT, as well as a high end inspiratory flow, EIF, immediately before interruption of inspiration augment exchange of $\mathrm{C} 02$ by reduction of airway and alveolar dead space.

\section{Objectives}

The hypothesis was tested that MDT and EIF affect C02 exchange in man without lung disease in principle as in ARDS. The study should provide guide lines in support of LPV at health as well as in lung disease.

\section{Methods}

During preparation for cerebral surgery in 8 patients without lung disease, breaths with 20 inspiratory wave forms were delivered with different inspiration time, $T_{I}$, post inspiratory pause time, $T_{P}$, and shape in form of ramps with increasing or decreasing flow rate. Signals for flow rate and $\mathrm{C} 02$ were analysed in the format of the single breath test $\mathrm{C} 02$ from which the volume of C02 eliminated during each ordinary or modified tidal breath, $\mathrm{V}_{\mathrm{T}} \mathrm{C02}$, was derived. Changes of $\mathrm{V}_{\mathrm{T}} \mathrm{C0} 2$ were explained by changes in airway dead space and by effects on intra-alveolar gas mixing inversely reflecting alveolar dead space.

'Lund University, Section of Clinical Physiology Department of Clinical

Sciences Lund, Lund, Sweden

Full list of author information is available at the end of the article

\section{Results}

In relation to ordinary breaths with $\mathrm{T}_{\mathrm{I}} 33 \%, \mathrm{~T}_{\mathrm{P}} 10 \%$ and square inspiratory flow, the change of $\mathrm{C} 02$ volume exchanged per breath, $\mathrm{DV}_{\mathrm{t}} \mathrm{C} 02 \%$, varied with $\mathrm{MDT}$ and EIF: $\mathrm{DV}_{\mathrm{t}} \mathrm{C} 02 \%=17 \cdot \ln \mathrm{MDT}+13 \cdot \mathrm{EIF}+1.4$

In each subject the influence of InMDT and EIF was highly significant. Positive effects on $\mathrm{C} 02$ exchange by longer MDT and higher EIF reflected both a reduced airway dead space and improved intra-alveolar gas mixing indicating a reduced alveolar dead space.

Modification of inspiratory flow pattern could increase $\mathrm{V}_{\mathrm{T}} \mathrm{C} 02$ by $17 \%$ at constant inspiratory flow and $27 \%$ at increasing inspiratory flow. The most efficient way to modify inspiration was to prolong $T_{P}$ at the expense of a shorter $\mathrm{T}_{\mathrm{I}}$ and eventually a shorter expiratory time. The more efficient $\mathrm{C} 02$ exchange allows a reduction of tidal volume by about $10 \%$.

\section{Conclusions}

Modification of inspiratory flow pattern, particularly by a longer $\mathrm{T}_{\mathrm{P}}$, is a tool for more efficient $\mathrm{C02}$ exchange that can easily be applied for lung protective ventilation at reduced tidal volume in patients without or with lung disease.

\section{Authors' details}

${ }^{1}$ Lund University, Section of Clinical Physiology Department of Clinical Sciences Lund, Lund, Sweden. 'Lund University, Section of Anaesthesia and Intensive Care, Department of Clinical Sciences Lund, Lund, Sweden.

Published: 1 October 2015

\section{Reference}

1. Aboab, Niklason, Uttman, Brochard, Jonson : Critical Care 2012.

doi:10.1186/2197-425X-3-S1-A309

Cite this article as: Jonson et al:: Modified inspiratory flow pattern - a tool for lung protective ventilation. Intensive Care Medicine Experimental 2015 3(Suppl 1):A309.

\section{SpringerOpen ${ }^{\circ}$}

(C) 2015 Jonson et al.; This is an Open Access article distributed under the terms of the Creative Commons Attribution License (http:// creativecommons.org/licenses/by/4.0), which permits unrestricted use, distribution, and reproduction in any medium, provided the original work is properly cited. 